Outline of Glossematics

A Study in the Methodology of the Humanities with Special Reference to Linguistics. Part 1: General Theory. By H. J. Uldall. (Travaux du Cercle Linguistique de Copenhague, Vol. 10 (1).) Pp. vi+ 90. (Copenhague : Nordisk Sprog- og Kulturforlag, 1957.) n.p.

7 HE subject of this book is not, as the title might lead one to suppose, a branch of linguistics; the author is inaugurating a new science, glossematic algebra, which shall be a formal non-quantitative technique of description in 'humanistic' disciplines such as linguistics and history. Pages 1-35 are occupied by general remarks on scientific method, like these : "the pragmatical scientists, never having found anything in a pure state of being, refuse to have anything to do with it" (p. 9) ; "Any post may bring the scientist news that. . . nothing, or very little, remains of the truths of yesterday" (p. 13). In the formal development of glossematic algebra that follows, the author begins by defining 'function' as "any dependence" and 'functive' as "anything that enters into a function" ; the discussion (pp. 36-41) is mado hard to follow by the use of a single symbol $\varphi$ (without subscripts) even in symbolizing situations that involve several functions. He next introduces a specific function, 'connexion' ('both-and'), which is commutative and associative; non-commutative algebras, we learn, are "extremely difficult" to design, and so devices for symbolizing the difference between the words 'fist' and 'fits' are postponed to the next instalment of this work. The next important concept is 'glossematic negation'; the author wishes to show symbolically that, for example, the phoneme which might, but does not, precede the [l] of "lay" is [p], rather than [s] or [k]. The rest of this fascicule is an elaborate set of formal schemata for descriptions, in terms of connexion and negation; some conerete examples are supplied, but these do not carry conviction that glossematic algebra is likely to be a fruitful study.

P. T. GEACH

\section{Lecture Experiments in Chemistry}

By G. Fowles. Fourth, revised edition. Pp. xvi+ 629. (London: G. Bell and Sons, Ltd., 1957.) 42s. net.

T HE author has added a number of new and interesting experiments to the fourth edition of this book. Thus, on the movement of molecules, the different rates at which hydrogen chloride and ammonia diffuse is illustrated by Prof. Watt's experiment of placing cotton-wool swabs, soaked in hydrochloric acid and aqueous ammonia respectively, at either end of a long tube, and noting the position at which a white ring first forms inside the tube. Similarly, the Brownian movement is demonstrated by a novel experiment using colloidal graphite. The major change in this edition is the recasting of Chapter 6 on physical principles, and the insertion of three new chapters on, respectively, surface chemistry, catalysis and combustion. The intensive study of colloids and adsorption, and their industrial applications, have introduced new processes and products into daily life, and this has enabled the author to describe a number of new experiments. Thus six pages are devoted to the use of ion-exchange resins, and the teacher will find the experiments with coloured ions of particular interest. In view of the size and scope of the book it is, however, a little disappointing to find only one experiment on paper chromatography. Small additions have been made to the appendixes and supplement at the end of the book; these include a short account of recent views on the teaching of chemistry, a few experiments, and further notes on some of the experiments previously described. Like its predecessors, this edition is a mine of useful information, and the revision has been well done apart from a few minor details, such as the descriptions of the mechanisms of the electrolysis of brine (p. 432) and the ferric sulphocyanide reaction (p. 413). The book is well produced and deserves the warm welcome which the other editions have received.

A. C. Caveli

\section{A Text Book of Theoretical and Inorganic Chem- istry}

By F. A. Philbrick and Dr. E. J. Holmyard. New revised edition by Dr. E. J. Holmyard and Dr. W. G. Palmer. Pp. ix +845. (London: J. M. Dent and Sons, Ltd., 1956.) 18s. 6d.

W HEN Dr. Palmer, of the University of Cam$W$ bridge, was called in as collaborator to help with the production of the 1949 edition of this book, he revised the whole physical chemistry section forming Part 2. He also re-wrote the section on valency, making of it a first-class self-contained article. In preparing the present edition, for which he alone is responsible, Dr. Palmer has thoroughly overhauled the descriptive matter forming Part 3 . He has replaced discarded explanations by modern ones; described new reagents, such as lithium aluminium hydride, thereby introducing better. methods of preparing diborane and silane ; described the use of deuterium and radioactive tracers in the elucidation of molecular structures; here and there deleted or added a few lines, occasionally recasting whole paragraphs. All the changes have been made so skilfully that the pagination is unchanged. There are few text-books of intermediate level combining in one volume both general and descriptive chemistry. Many will be pleased that one of the best of the few has once more been brought up to date.

G. Fowles

The World of Learning, 1957

Eighth edition. Pp. xxxii +1038 . (London : Europa Publications, Ltd., 1957.) 120s. net.

"r HERE is little room for ornament or artifice in a work of reference. It relies for its effect on the austere beauty of facts." Thus claim the editors of this book. It is doubtful whether there is another volume with so much austere beauty between its covers. "The World of Learning", which has run to eight editions in ten years, lists the academies, learned societies, museums, universities, art galleries and libraries of the whole world, together with their professors, members, curators, presidents and secretaries. One can look up the number of books in the library of the Université d'Haiti or the date of foundation of the West African Cocoa Research Institute. There are a list of publications issued by each institution and a big section on Unesco. Unfortunately, owing to its size, this book omits an index of names-it is possible to look under the University of $X$ and find Dr. $Y . Z$. works there, but not to look up Dr. Y.Z. in order to find where he does work. Nevertheless, there are few other books with so much readily available, useful and up-to-date information about the world of learning. 